\title{
Water uptake dynamics under progressive drought stress in diverse accessions of the OryzaSNP panel of rice (Oryza sativa)
}

\author{
Veeresh R. P. Gowda ${ }^{\mathrm{A}, \mathrm{B}}$, Amelia Henry ${ }^{\mathrm{A}, \mathrm{E}}$, Vincent Vadez ${ }^{\mathrm{C}}$, H. E. Shashidhar ${ }^{\mathrm{B}}$ \\ and Rachid Serraj ${ }^{\mathrm{A}, \mathrm{D}}$ \\ Anternational Rice Research Institute, DAPO Box 7777, Metro Manila 1301, Philippines. \\ ${ }^{B}$ Department of Biotechnology, College of Agriculture, University of Agricultural Sciences, \\ GKVK, Bangalore 560065, India. \\ CInternational Crops Research Institute for the Semiarid Tropics, Patancheru, Hyderabad, Andra Pradesh, India. \\ Deresent address: International Centre for Agricultural Research in the Dry Areas, Aleppo, Syria. \\ ${ }^{\mathrm{E}}$ Corresponding author. Email: a.henry@irri.org
}

\begin{abstract}
In addition to characterising root architecture, evaluating root water uptake ability is important for understanding drought response. A series of three lysimeter studies were conducted using the OryzaSNP panel, which consists of 20 diverse rice (Oryza sativa L.) genotypes. Large genotypic differences in drought response were observed in this genotype panel in terms of plant growth and water uptake. Total water uptake and daily water uptake rates in the droughtstress treatment were correlated with root length density, especially at depths below $30 \mathrm{~cm}$. Patterns of water uptake among genotypes remained consistent throughout the stress treatments: genotypes that initially extracted more water were the same genotypes that extracted more water at the end of the study. These results suggest that response to drought by deep root growth, rather than a conservative soil water pattern, seems to be important for lowland rice. Genotypes in the $O$. sativa type aus group showed some of the greatest water uptake and root growth values. Since the OryzaSNP panel has been genotyped in detail with SNP markers, we expect that these results will be useful for understanding the genetics of rice root growth and function for water uptake in response to drought.
\end{abstract}

Additional keywords: genotypes, lowland soil, lysimeter, root.

Received 19 January 2012, accepted 16 March 2012, published online 27 April 2012

\section{Introduction}

Among reported drought-response traits, root-related attributes are thought to be the most promising for conferring drought resistance (Lynch 2007; Serraj et al. 2009; Gowda et al. 2011). Most root research for drought-resistant rice (Oryza sativa L.) has focussed on characterising root architecture, especially root growth at depth, in response to drought in different agroecological systems (Gowda et al. 2011). Continued ability to take up water under dry soil conditions through accessing greater volumes of soil via deep root growth is thought to be an important factor for drought response in rice (Lilley and Fukai 1994). However, little is known about the variability in water uptake ability among rice genotypes. In addition to a relatively shallow root system, rice has been characterised to have lower water uptake ability per length of root than other crops (Kondo et al. 2000). Drought resistance has been found to be related to deep root growth and water uptake ability in both upland and lowland ecologies (as reviewed by Gowda et al. 2011). However, upland and lowland ecologies differ in their typical patterns of soil drying; specifically, upland soils (granulated soils) show much faster drainage rates than lowland soils (puddled soils; Sanchez 1973). These differences in soil drying patterns may necessitate different mechanisms for drought response in lowland and upland ecologies.

Upland-adapted rice genotypes in general are thought to have deeper roots than lowland genotypes (O'Toole and Bland 1987). Lafitte et al. (2001) characterised differences in root growth among rice types (isoenzyme groups) and concluded that upland-adapted genotypes across isoenzyme groups showed greater root growth at depth. However, lowland rice shows genotypic variability in their ability to increase deep root growth in response to drought. Henry et al. (2011) reported that out of 20 diverse genotypes, all had some ability to increase root length density (RLD) at depth with increasing severity of drought stress, although each to a different extent.

In addition to environmental factors such as soil moisture, light levels and vapour pressure deficit, rice water uptake has been documented to be related to transpiration efficiency (Impa et al. 2005; Haefele et al. 2009; Parent et al. 2010), hydraulic conductance (Hirasawa and Ishihara 1991; Kato and Okami 
2011), and root growth at depth (Puckridge and O'Toole 1980; Lilley and Fukai 1994). Although variation in root architecture can increase the amount of available water accessible for uptake under drought stress, RLD or root mass density and its distribution by depth does not explain all of the genetic variation in water uptake ability of rice under drought (Kamoshita et al. 2000; Henry et al. 2011), as is the case in other crops such as chickpea (Cicer arietinum L.) (Zaman-Allah et al. 2011a) or groundnut (Arachis hypogaea L.) (Ratnakumar and Vadez 2011). Therefore, it is necessary to analyse the genetic basis of water uptake ability under drought in addition to understanding differences in root architecture and morphology. Although several quantitative trait loci have been identified for drought resistance and root-related traits (see reviews by Kamoshita et al. (2008) and Gowda et al. (2011)), more investigation on the genetics and functionality of root systems (i.e. water uptake ability) is needed to dissect the genetic basis of dehydration avoidance and root traits (Serraj et al. 2011). The genetic material used for this work was the OryzaSNP panel (McNally et al. 2009), comprising 20 diverse rice accessions from the $O$. sativa type aus, $O$. sativa type indica and $O$. sativa type japonica groups adapted to a range of ecologies that have been genotyped with 160000 SNP markers and selected to represent diversity in rice. This set of genotypes has already been used for association mapping of genes related to shoot traits (Jahn et al. 2011), and our study was conducted as part of an effort that will, in subsequent studies, link root morphological and functional traits with genomic regions.

In this study, we investigated genetic diversity for root growth and water uptake in terms of rate and patterns during progressive drought stress. We focused on rainfed lowland conditions, which occur in bunded fields without irrigation that are prone to a range of stresses, including soil drying following flooded conditions (Wade et al. 1999). The onset of drought stress in rainfed lowland fields typically progresses more slowly than in upland fields, in which the soil is maintained under aerobic conditions, but drought stress in rainfed lowland fields can become very severe in terms of yield reductions (Serraj et al. 2009). In order to investigate root growth, water uptake and shoot growth, a series of lysimetric experiments were conducted using the OryzaSNP rice panel under well watered and droughtstress conditions. We hypothesised that genetic variation in water uptake ability would be closely related to a genotype's ability to respond to progressive drought stress by increasing root length at depth and therefore water extraction.

\section{Materials and methods}

\section{Experimental setup}

Oryza sativa L. accessions from the OryzaSNP panel - O. sativa type aus var. Dular, FR13A, N22 and Rayada; $O$. sativa type indica var. Aswina, IR64, Minghui 63, Pokkali, Sadu Cho, SHZ2, Swarna and Zhenshan 97B; O. sativa type japonica var. Azucena, Cypress, Dom Sufid, LTH, M202, Moroberekan, Nipponbare and Tainung $67-$ were obtained from the T.T. Chang Genetic Resources Genebank at the International Rice Research Institute (IRRI). Three lysimeter experiments were conducted (summarised in Table 1). Experiment (Exp) 1 (2008 wet season September to December) and Exp 3 (2009 wet season - June to September) were conducted in a greenhouse at IRRI, Los Baños, Philippines $\left(14^{\circ} \mathrm{N}, 121^{\circ} \mathrm{E}, 21 \mathrm{~m}\right.$ above sea level (a.s.1.)), and Exp 2 (2009 dry season - January to April) was conducted in the lysimetric facility (Vadez et al. 2008), equipped with a rainout shelter, at the International Crops Research Institute for the Semiarid Tropics (ICRISAT), Patancheru, India $\left(17^{\circ} 30^{\prime} \mathrm{N}\right.$, $78^{\circ} 16^{\prime} \mathrm{E}$, altitude $549 \mathrm{~m}$ a.s.1.). Mean outdoor temperatures and solar radiation levels were generally highest and relative humidity was lowest during Exp 2 (Table 1).

Table 1. Summary of three lysimeter experiments conducted for water uptake measurements of the OryzaSNP panel under drought stress (DS) and well watered (WW) treatments

masl, metres above sea level; DAS, days after sowing; IRRI, International Rice Research Institute; ICRISAT, International Crops Research Institute for the Semiarid Tropics

\begin{tabular}{|c|c|c|c|}
\hline Experiment & 1 & 2 & 3 \\
\hline Institute & IRRI, Philippines & ICRISAT, India & IRRI, Philippines \\
\hline Year and season & 2008 wet season & 2009 dry season & 2009 wet season \\
\hline Latitude and longitude & $14^{\circ} \mathrm{N}, 121^{\circ} \mathrm{E}$ & $17^{\circ} 30^{\prime} \mathrm{N}, 78^{\circ} 16^{\prime} \mathrm{E}$ & $14^{\circ} \mathrm{N}, 121^{\circ} \mathrm{E}$ \\
\hline Altitude (masl) & 21 & 549 & 21 \\
\hline Site & $\begin{array}{l}\text { Greenhouse } \\
\text { (fully covered) }\end{array}$ & $\begin{array}{l}\text { Movable rainout } \\
\text { shelter }\end{array}$ & $\begin{array}{l}\text { Greenhouse } \\
\text { (fully covered) }\end{array}$ \\
\hline Mean solar radiation $\left(\mathrm{MJ} \mathrm{m}^{-2} \mathrm{~d}^{-1}\right)$ & 15.5 & 20.0 & 14.5 \\
\hline $\begin{array}{l}\text { Mean outdoor temperatures }\left({ }^{\circ} \mathrm{C}\right) \\
\quad(\text { minimum- maximum })\end{array}$ & $24.4-31.6$ & $20.1-36.6$ & $24.8-31.6$ \\
\hline Mean relative humidity (\%) & 85.2 & 46.3 & 87.1 \\
\hline Lysimeter size (diameter $\times$ length; $\mathrm{cm})$ & $19 \times 105$ & $20 \times 120$ & $19 \times 105$ \\
\hline Lysimeter colour & Painted white & Light grey & Painted white \\
\hline Soil type & Mollisol & Vertisol & Mollisol \\
\hline Soil bulk density $\left(\mathrm{g} \mathrm{cm}^{-3}\right)$ & 1.28 & 1.40 & 1.28 \\
\hline Initiation of stress imposition (DAS) & 44 & 70 & 33 \\
\hline Root sampling (DAS) & 74 & 96 & Not sampled \\
\hline $\begin{array}{l}\text { Stress severity: reduction in shoot dry } \\
\text { weight (DS : WW, \%) }\end{array}$ & 49 & 60 & Not sampled \\
\hline
\end{tabular}


Lysimeters were constructed from polyvinyl chloride (PVC) cylinders of $19 \mathrm{~cm}$ diameter and $105 \mathrm{~cm}$ height (Exps 1 and 3) or $20 \mathrm{~cm}$ in diameter and $120 \mathrm{~cm}$ in height (Exp 2), sealed at the bottom (with drainage holes) and lined with a plastic membrane. The PVC cylinders used in Exps 1 and 3 were painted white; for Exp 2, the cylinders were light grey. Soil was collected from the top layer of upland and lowland fields of IRRI (mollisol) and at ICRISAT (vertisol). The upland soil was used in the bottom part of each cylinder and the lowland paddy soil was used in the top part. Before being packed into cylinders, the upland soil was sieved and air-dried, and lowland soil was cleaned of debris but maintained saturated. Each lysimeter was filled with $29 \mathrm{~kg}$ of soil (Exps 1 and 3) or $44 \mathrm{~kg}$ (Exp 2) to a height of $100 \mathrm{~cm}$ to achieve a bulk density of $1.28 \mathrm{~g} \mathrm{~cm}^{-3}$ (Exps 1 and 3) or $1.40 \mathrm{~g} \mathrm{~cm}^{-3}$ (Exp 2). While filling, the soil was shaken and compacted with a circular metal plate in increments of $5 \mathrm{~cm}(\operatorname{Exps} 1$ and 3$)$ or $5 \mathrm{~kg}(\operatorname{Exp} 2)$ to achieve a uniform bulk density throughout the soil column. In Exps 1 and 3, the top $20 \mathrm{~cm}$ of each lysimeter was filled with puddled lowland soil. This method was intended to simulate lowland field conditions as closely as possible. In Exp 1, a basal application of $5.9 \mathrm{~g}$ per lysimeter of complete fertiliser (14N$14 \mathrm{P}_{2} \mathrm{O}_{5}-14 \mathrm{~K}_{2} \mathrm{O}$; Quezon Farmers, Laguna, Philippines) was applied before transplanting, and an additional $5.8 \mathrm{~g}$ per lysimeter of urea was applied at 35 days after sowing (DAS). In Exp 2, $5.72 \mathrm{~g} \mathrm{~N}, 3.85 \mathrm{~g} \mathrm{P}_{2} \mathrm{O}_{5}$, and $2.17 \mathrm{~g} \mathrm{~K}_{2} \mathrm{O}$ were applied to each lysimeter before transplanting. Fertiliser in Exp 3 was applied at 30 days after transplanting at the same rates as in Exp 1. Seedlings were transplanted at 14 DAS (Exp 1, one seedling per pot) and 29 DAS (Exp 2, four seedlings thinned to one after 7 days). In Exp 3, five pre-germinated seeds were sown by hand dibble, then thinned to one plant per lysimeter at the three-leaf stage. The delayed transplanting in Exp 2 was due to low temperatures at the start of the experiment that slowed seedling establishment. In all experiments, lysimeters were arranged in a completely randomised block design with five replications in both treatments (drought-stress and well watered) within cement-lined open-top tanks in the greenhouse or rainout shelter. Plants in both treatments were watered every other day until the drought stress was imposed at 44, 70 and 33 DAS (Exps 1, 2 and 3) by opening the drainage holes at the bottom of each lysimeter. Genotypes differed in growth stage at the time of draining due to differences in maturity duration. To reduce water loss due to evaporation from the soil surface, each lysimeter in the drought-stress treatment was covered with two layers of plastic sheet (Exps 1 and 3) or $500 \mathrm{~g}$ of 3-4-mm white plastic beads (Exp 2). Plants in the control treatment of all experiments were maintained completely saturated with standing water above the soil surface throughout the studies.

\section{Water uptake measurements}

Water uptake in the drought-stress treatment was measured by weighing once per week in Exp 1 (50, 57, 65 and 73 DAS), twice per week in $\operatorname{Exp} 2(73,79,82,86,89,92$ and 97 DAS), and once per week for the first 3 weeks $(33,40,47$ and 54 DAS) and twice per week for the last 2 weeks $(58,61,66$ and 68 DAS) in Exp 3. In Exp 1, each lysimeter was weighed using a $65-\mathrm{kg}$ balance with suspended weighing option (Kern model FRB65 K0.5, Kern and Sohn GmbH, Balingen, Germany) attached to a mechanical hoist
(Shop Star Electric Chain Hoist, Columbus McKinnon Corp., Amherst, NY, USA). In Exp 2, lysimeters were weighed using an S-type load cell (Mettler-Toledo, Geneva, Switzerland) of $100 \mathrm{~kg}$ capacity with 10 -g precision, using a manual chain-block pulley as described by Zaman-Allah et al. (2011a). In Exp 3, lysimeter weights were measured with a 91-kg load cell (Omega LCCD-200, Omega Engineering, Inc., Stamford, CT, USA) mounted on a mechanical hoist from a rolling rack above each planted tank in the greenhouse.

Water uptake was calculated in the drought-stress treatments as the difference between the initial weight after draining and the lysimeter weight at different times throughout each experiment. Cumulative water uptake was calculated as the amount of water lost from the lysimeters over the course of the drought-stress treatment. Water uptake rates were calculated as the difference between lysimeter weights on two subsequent dates. To account for differences in plant size, water uptake rates were also normalised by dividing the rate on each measurement date by the water uptake rate at the start of the drought stress. Absolute and normalised rates are reported here.

\section{Root and shoot measurements}

Roots were sampled at 74 DAS in Exp 1 and at 98 DAS in Exp 2. For root sampling, the plastic liners were pulled out of the lysimeters and maximum root depth was measured by noting the deepest root from the bottom of the soil column. In Exp 1, roots were sampled by separating the soil into four sections $(0-30 \mathrm{~cm}$, $30-45 \mathrm{~cm}, 45-60 \mathrm{~cm}$ and $60-100 \mathrm{~cm})$. In Exp 2, the entire root zone was harvested but not separated into sections by depth. Root measurements were taken in the stress treatment in Exps 1 and 2 as well as in the control treatment of Exp 1. In Exp 2, only selected genotypes showing contrasting water uptake under drought stress were selected for root sampling. Roots and shoots were not sampled in Exp 3.

Roots were separated from soil by gently spraying tap water over samples placed on a 1-mm screen (Exp 1) or stacked 1-mm and 2-mm sieves (Exp 2) until all soil washed through the screen. After cleaning, roots were stored in an alcohol solution $(50 \%$ isopropanol) at $4{ }^{\circ} \mathrm{C}$. After washing, roots were spread out on Plexiglas trays $(200 \times 300 \mathrm{~mm})$ with a 3- to 4-mm layer of water and scanned (Epson Perfection V700, Epson America, Long Beach, CA, USA) at a resolution of $400 \mathrm{dpi}$. The captured grayscale images were analysed using image analysis software (WinRhizo, Regent Instruments, Quebec, Canada) to determine root length. RLD $\left(\mathrm{cm} \mathrm{cm}^{-3}\right)$ was calculated by dividing the root length by the soil volume at each soil section. Root dry weight (RDW) was determined for each plant and the root: shoot ratio (RSR) was calculated by dividing RDW by shoot dry weight (SDW). At the end of Exps 1 and 2, plants were cut at crown level and dried to determine SDW.

\section{Data analysis}

ANOVA on data for all three experimental datasets was carried out separately using the aov (ANOVA), Im (linear regression) and asremL (mixed model for repeated-measures) procedures in R (R Development Core Team 2010). Significant differences among genotypes for all traits were determined by Tukey's Honestly Significant Difference (HSD) test at a significance 
level of 0.05 for ANOVA and LSD for repeated measures. A Pearson correlation matrix ('correlation' procedure) was conducted using water uptake and plant growth parameters from Exps 1 and 2 in R.

\section{Results}

\section{Genetic variability of root and shoot traits}

Plant growth was differentially affected by the drought treatment depending on experimental conditions. Exp 2 showed a more pronounced decrease in RDW and SDW than Exp 1 (Fig. 1). Drought stress reduced average SDW by $49 \%$ in Exp 1 $(P<0.001)$ and by $60 \%$ in Exp 2 compared with the control. RDW was $60 \%$ lower in the drought treatment than in the control treatment in Exp $1(P<0.001)$, but did not differ between treatments in Exp 2. RDW was greatest in genotypes Dular (Exps 1 and 2) and N22 (Exp 1; Fig. 1). The average RSR did not differ significantly between the stress and control treatments

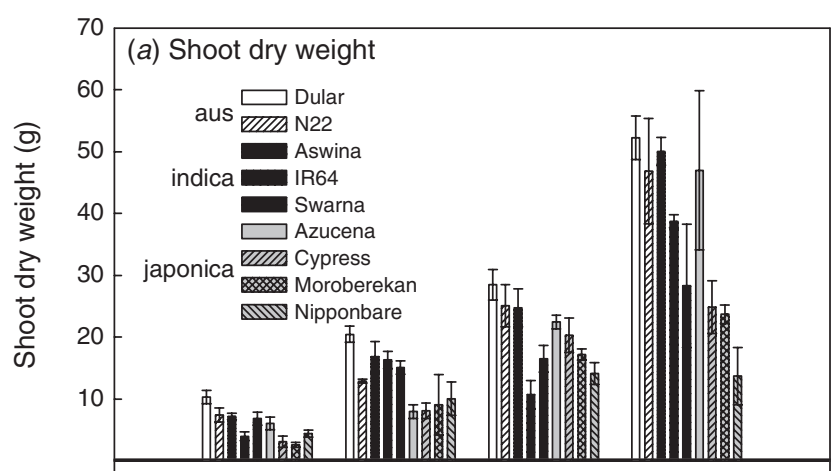

(b) Root dry weight

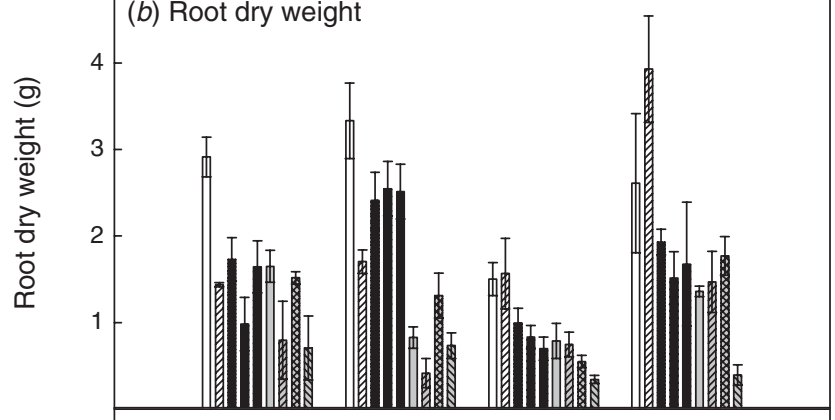

(c) Root:shoot ratio

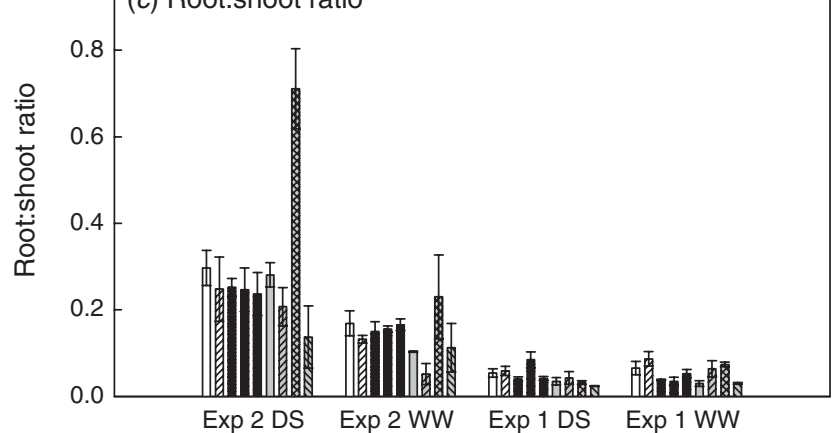

Fig. 1. (a) Shoot dry weight, (b) root dry weight, and (c) root: shoot ratios in Experiments 1 and 2 of two Oryza sativa type aus (white bars), three $O$. sativa type indica (black bars) and four O. sativa type japonica genotypes (grey bars). Values shown are means \pm s.e. in Exp 1, but was 22\% (Nipponbare) to 303\% (Cypress) greater in each genotype of the drought-stress treatment in Exp 2 $(P<0.001$; Fig. 1). Moroberekan stood out as having the greatest increase in RSR as the average experimental shoot mass decreased (Fig. 1). In general, O. sativa type japonica genotypes showed lower shoot and root biomass values.

RLD in Exp 1 declined markedly from the surface to the base of the lysimeters, but most genotypes showed greater RLD below $30 \mathrm{~cm}$ in the drought-stress treatment compared with the well watered control (Table 2). Although large numerical differences in RLD were observed among genotypes, few were significantly different due to experimental errors commonly associated with root measurements. Genotypes Aswina, Dular, FR13A, Azucena, N22 and Rayada had the greatest RLD $\left(>0.30 \mathrm{~cm} \mathrm{~cm}^{-3}\right)$ at $60-100 \mathrm{~cm}$ soil depth.

\section{Water uptake dynamics under drought stress}

Significant differences among genotypes were observed for total water uptake (TWU) in $\operatorname{Exp} 1(P=0.03)$, Exp 2 $(P=0.002)$ and $\operatorname{Exp} 3(P=0.001 ;$ Fig. 2$)$. Dular, Azucena, Aswina and N22 showed greater cumulative water uptake during the stress treatment in all three experiments $(>4.5 \mathrm{~kg}$ in Exp 1, 4.0 kg in Exp 2 and $5.8 \mathrm{~kg}$ in Exp 3) than IR64 and Nipponbare $(<3.15 \mathrm{~kg}$ in Exp $1,3.1 \mathrm{~kg}$ in Exp 2 and $4.65 \mathrm{~kg}$ in Exp 3). Among the rice types studied, O. sativa type aus accessions showed the greatest TWU in Exp $2(P=0.006)$ and Exp $3(P<0.001)$, whereas $O$. sativa type japonica types showed the least water uptake (Table 3). Rates of water uptake also varied among genotypes and with time (Figs 3,4). As drought stress progressed in all experiments, genotypes Aswina, Azucena and Dular showed the highest water uptake rates. IR64, LTH and Nipponbare stood out as consistently having the lowest water uptake rates, except at the beginning of the drought-stress treatment of Exp 2, when LTH showed the highest water uptake rates (Fig. 3).

To account for differences in plant size among genotypes of this diverse panel, water uptake rates were normalised by initial water uptake rates at the onset of the drought-stress treatment. Genotypes identified as most contrasting differed between nonnormalised (Fig. 3) and normalised water uptake rates (Fig. 4): Azucena, Dular and FR13A showed the highest normalised water uptake rates, whereas Cypress, IR64 and LTH showed the lowest normalised water uptake rates. TWU per total root length (TRL) in each lysimeter differed among genotypes $(P=0.003$ and $P=0.001)$ and among types $(P=0.006$ and $P=0.007)$ in Exps 1 and 2, respectively (Fig. 5). O. sativa type aus types showed the lowest TWU TRL ${ }^{-1}$ values, whereas the $O$. sativa type japonica group showed higher TWU TRL ${ }^{-1}$ values in both experiments. SHZ2 (Exp 1) and Cypress (Exp 2) had the highest TWU TRL ${ }^{-1}$, and Rayada (Exp 1) and Dular (Exp 2) showed the lowest TWU TRL ${ }^{-1}$ values (data not shown).

The relationships between water uptake and shoot and root traits under drought stress were examined by means of correlation analysis in Exps 1 and 2 (Table 4). In Exp 1, the relationship between water uptake and RLD increased in significance with increasing depth in the lysimeter. In both experiments, SDW showed a significant relationship with TWU and final water uptake rate, but not with normalised final water uptake rates. 
Table 2. Root length density (RLD) (in $\mathrm{cm} \mathrm{cm}^{-3}$ ) with depth in the well watered control (WW) and drought-stress (DS) treatments in Experiments 1 and 2

Letters indicate significant differences among types. Genotypes in each group were Oryza sativa type aus (Dular, FR13A, N22 and Rayada), O. sativa type indica (Aswina, IR64, Minghui 63, Pokkali, Sadu Cho, SHZ2, Swarna and Zhenshan 97B) and O. sativa type japonica (Azucena, Cypress, Dom Sufid, LTH, M202, Moroberekan, Nipponbare and Tainung 67). $P$-value indicates the significance level among genotypes and types at each depth based on ANOVA

\begin{tabular}{|c|c|c|c|c|c|c|c|c|c|c|}
\hline & \multicolumn{5}{|c|}{ WW } & \multicolumn{5}{|c|}{ DS } \\
\hline & \multirow[b]{2}{*}{$0-30 \mathrm{~cm}$} & \multicolumn{2}{|c|}{ Exp 1} & \multirow[b]{2}{*}{$60-100 \mathrm{~cm}$} & \multirow{2}{*}{$\begin{array}{c}\text { Exp 2 } \\
0-120 \mathrm{~cm}\end{array}$} & \multicolumn{4}{|c|}{ Exp 1} & \multirow{2}{*}{$\begin{array}{c}\text { Exp 2 } \\
0-120 \mathrm{~cm}\end{array}$} \\
\hline & & $30-45 \mathrm{~cm}$ & $45-60 \mathrm{~cm}$ & & & $0-30 \mathrm{~cm}$ & $30-45 \mathrm{~cm}$ & $45-60 \mathrm{~cm}$ & $60-100 \mathrm{~cm}$ & \\
\hline Aswina & $1.91 \mathrm{~b}$ & 0.73 & 0.05 & 0 & $1.25 \mathrm{ab}$ & $0.70 \mathrm{ab}$ & $2.41 \mathrm{ab}$ & $1.56 \mathrm{ab}$ & 0.42 & $0.76 \mathrm{abc}$ \\
\hline Azucena & $2.07 \mathrm{~b}$ & 1.51 & 0.19 & 0.01 & $0.25 \mathrm{c}$ & $0.60 \mathrm{~b}$ & $1.31 \mathrm{~b}$ & $1.23 \mathrm{ab}$ & 0.3 & $0.65 \mathrm{bc}$ \\
\hline Cypress & $2.54 \mathrm{~b}$ & 0.04 & 0 & 0 & $0.25 \mathrm{c}$ & $0.61 \mathrm{~b}$ & $1.27 \mathrm{~b}$ & $0.62 \mathrm{ab}$ & 0.11 & $0.34 \mathrm{bc}$ \\
\hline Dom Sufid & $2.77 \mathrm{~b}$ & 0.88 & 0.2 & 0.02 & - & $1.10 \mathrm{ab}$ & $1.15 \mathrm{~b}$ & $1.10 \mathrm{ab}$ & 0.16 & - \\
\hline Dular & $2.50 \mathrm{~b}$ & 1.61 & 0.15 & 0 & $1.34 \mathrm{a}$ & $1.20 \mathrm{ab}$ & $1.60 \mathrm{ab}$ & $1.36 \mathrm{ab}$ & 0.36 & $1.32 \mathrm{a}$ \\
\hline FR13A & $4.51 \mathrm{~b}$ & 1.58 & 0.22 & 0 & - & $0.60 \mathrm{~b}$ & $1.41 \mathrm{~b}$ & $1.17 \mathrm{ab}$ & 0.4 & - \\
\hline IR 64 & $2.23 \mathrm{~b}$ & 0.07 & 0 & 0 & $1.15 \mathrm{ab}$ & $1.43 \mathrm{ab}$ & $0.99 b$ & $0.74 \mathrm{ab}$ & 0.03 & $0.79 a b c$ \\
\hline LTH & $2.09 \mathrm{~b}$ & 0.12 & 0 & 0 & - & $1.12 \mathrm{ab}$ & $0.73 b$ & $0.25 \mathrm{ab}$ & 0.02 & - \\
\hline M 202 & $2.84 b$ & 0.38 & 0.01 & 0 & - & $0.90 \mathrm{ab}$ & $0.94 b$ & $0.28 \mathrm{ab}$ & 0.03 & - \\
\hline Minghui 63 & $1.54 \mathrm{~b}$ & 0.63 & 0.06 & 0 & - & $0.60 \mathrm{~b}$ & $0.68 b$ & $0.45 \mathrm{ab}$ & 0.07 & - \\
\hline Moroberekan & $2.40 \mathrm{~b}$ & 0.29 & 0 & 0 & $0.46 \mathrm{c}$ & $0.39 \mathrm{~b}$ & $0.52 \mathrm{~b}$ & $0.19 \mathrm{ab}$ & 0.04 & $0.81 \mathrm{abc}$ \\
\hline $\mathrm{N} 22$ & $5.01 \mathrm{~b}$ & 2.03 & 0.16 & 0 & $0.68 b c$ & $1.16 \mathrm{ab}$ & $2.27 \mathrm{ab}$ & $1.78 \mathrm{ab}$ & 0.39 & $0.60 \mathrm{bc}$ \\
\hline Nipponbare & $1.12 \mathrm{~b}$ & 0 & 0 & 0 & $0.36 \mathrm{c}$ & $0.45 b$ & $0.55 b$ & $0.14 \mathrm{ab}$ & 0.01 & $0.17 \mathrm{c}$ \\
\hline Pokkali & $3.62 \mathrm{~b}$ & 1.81 & 0 & 0 & - & $1.60 \mathrm{ab}$ & $1.29 \mathrm{~b}$ & $0.45 \mathrm{ab}$ & 0.03 & - \\
\hline Rayada & $12.87 \mathrm{a}$ & 1.02 & 0 & 0 & - & $1.95 \mathrm{a}$ & $3.77 \mathrm{a}$ & $1.84 \mathrm{a}$ & 0.37 & - \\
\hline Sadu Cho & $4.90 \mathrm{~b}$ & 0.5 & 0.07 & 0 & - & $0.82 \mathrm{ab}$ & $0.50 \mathrm{~b}$ & $0.32 \mathrm{ab}$ & 0.05 & - \\
\hline Shan Huang Zhan 2 & $2.48 \mathrm{~b}$ & 0.43 & 0.06 & 0 & - & $0.33 b$ & $0.23 b$ & $0.04 b$ & 0 & - \\
\hline Swarna & $3.44 b$ & 0.86 & 0.01 & 0 & $1.25 \mathrm{ab}$ & $1.62 \mathrm{ab}$ & $1.09 \mathrm{~b}$ & $0.35 \mathrm{ab}$ & 0.07 & $0.97 \mathrm{ab}$ \\
\hline Tainung 67 & $3.42 \mathrm{~b}$ & 0.41 & 0 & 0 & - & $0.64 \mathrm{ab}$ & $0.65 b$ & $0.45 \mathrm{ab}$ & 0.1 & - \\
\hline Zhenshan 97B & $2.85 \mathrm{~b}$ & 0.62 & 0.04 & 0 & - & $0.73 \mathrm{ab}$ & $1.03 \mathrm{~b}$ & $0.73 \mathrm{ab}$ & 0.11 & - \\
\hline$O$. sativa type aus & $6.06 \mathrm{a}$ & $1.56 \mathrm{a}$ & 0.12 & $<0.001$ & $1.09 \mathrm{a}$ & $1.22 \mathrm{a}$ & $2.26 \mathrm{a}$ & $1.55 \mathrm{a}$ & $0.37 \mathrm{a}$ & $0.96 \mathrm{a}$ \\
\hline$O$. sativa type indica & $2.86 \mathrm{~b}$ & $0.68 \mathrm{~b}$ & 0.04 & $<0.001$ & $1.22 \mathrm{a}$ & $0.97 \mathrm{ab}$ & $1.00 \mathrm{~b}$ & $0.56 \mathrm{~b}$ & $0.09 \mathrm{~b}$ & $0.83 \mathrm{ab}$ \\
\hline O. sativa type japonica & $2.40 \mathrm{~b}$ & $0.52 b$ & 0.05 & 0.004 & $0.32 b$ & $0.71 b$ & $0.92 b$ & $0.56 \mathrm{~b}$ & $0.10 \mathrm{~b}$ & $0.47 \mathrm{~b}$ \\
\hline \multicolumn{11}{|l|}{$P$-values } \\
\hline Type & $<0.001$ & 0.003 & 0.078 & 0.32 & $<0.001$ & 0.018 & $<0.001$ & $<0.001$ & $<0.001$ & 0.006 \\
\hline Genotype & $<0.001$ & 0.016 & 0.128 & 0.515 & $<0.001$ & $<0.001$ & $<0.001$ & $<0.001$ & $<0.001$ & $<0.001$ \\
\hline
\end{tabular}

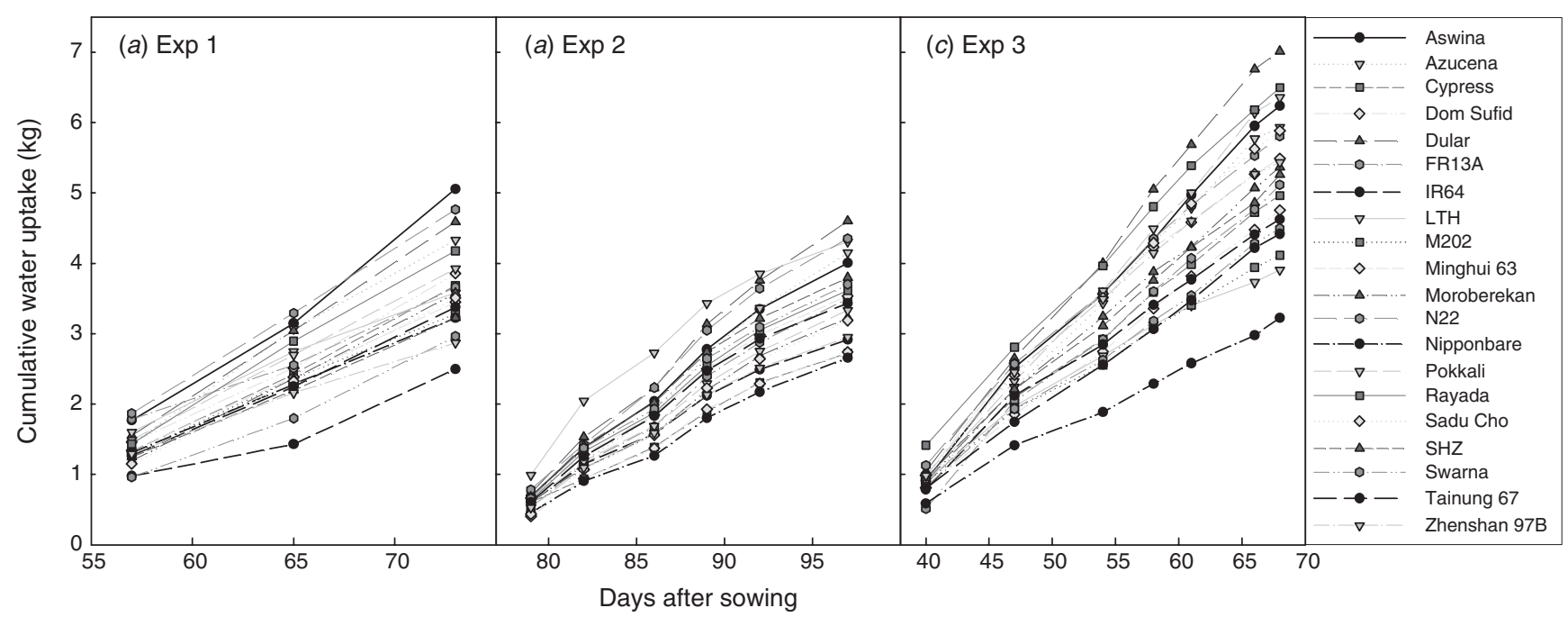

Fig. 2. Cumulative water uptake after draining in drought treatments of the three lysimeter studies in this experiment. (a) Experiment (Exp) $1,(b)$ Exp 2 and (c) Exp 3. 
Table 3. Mean total water uptake (TWU) of genotypes from the OryzaSNP panel belonging to different rice types under drought stress in three lysimeter experiments

Genotypes in each group were Oryza sativa type aus (Dular, FR13A, N22 and Rayada), O. sativa type indica (Aswina, IR64, Minghui 63, Pokkali, Sadu Cho, SHZ2, Swarna and Zhenshan 97B) and O. sativa type japonica (Azucena, Cypress, Dom Sufid, LTH, M202, Moroberekan, Nipponbare and Tainung 67). Letters indicate significant differences among types $(P<0.05)$. Types did not differ significantly in Experiment 1. No. gen, number of genotypes in each group; DAS, days after sowing; WS, wet season; DS, dry season; IRRI, International Rice Research Institute; ICRISAT; International Crops Research Institute for the Semiarid Tropics

\begin{tabular}{|c|c|c|c|c|c|c|}
\hline \multirow{4}{*}{$\begin{array}{l}\text { Experiment } \\
\text { Season } \\
\text { Stress duration } \\
\text { Type }\end{array}$} & \multicolumn{2}{|c|}{1} & \multicolumn{2}{|c|}{2} & \multicolumn{2}{|c|}{3} \\
\hline & \multicolumn{2}{|c|}{ WS 2008, IRRI } & \multicolumn{2}{|c|}{ DS 2009, ICRISAT } & \multicolumn{2}{|c|}{ WS 2009, IRRI } \\
\hline & 29 day & 73 DAS) & $27 \mathrm{da}$ & 97 DAS) & $35 \mathrm{~d}$ & 68 DAS) \\
\hline & No. gen. & TWU (kg) & No. gen. & TWU (kg) & No. gen. & TWU (kg) \\
\hline aus & 4 & $4.15 \pm 0.27$ & 4 & $4.02 \pm 0.17 \mathrm{a}$ & 4 & $6.11 \pm 0.26 \mathrm{a}$ \\
\hline indica & 8 & $3.46 \pm 0.20$ & 8 & $3.42 \pm 0.12 b$ & 8 & $5.47 \pm 0.24 a$ \\
\hline japonica & 8 & $3.64 \pm 0.15$ & 7 & $3.24 \pm 0.19 b$ & 8 & $4.55 \pm 0.21 b$ \\
\hline
\end{tabular}

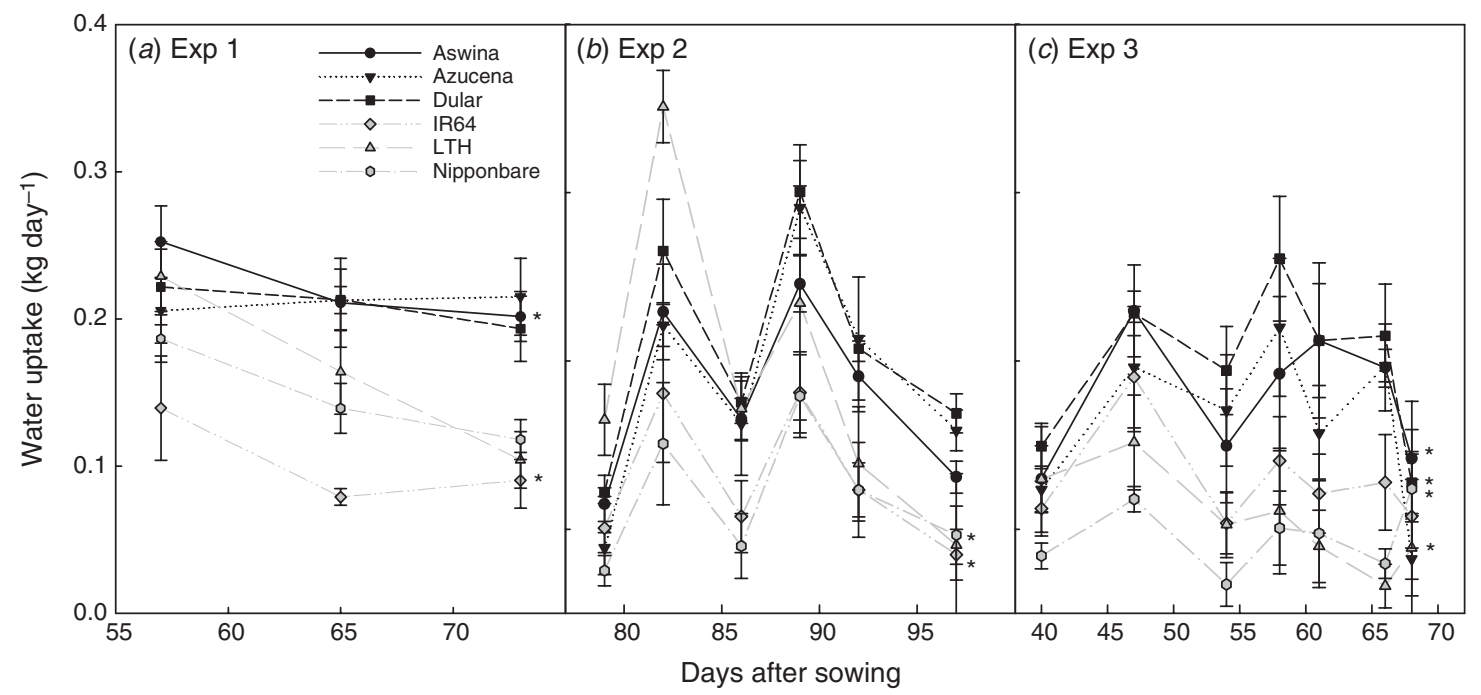

Fig. 3. Rates of plant water uptake during the drought stress treatment of (a) Experiment (Exp) 1, (b) Exp 2 and (c) Exp 3. For clarity, only the six most contrasting genotypes for water uptake rates are shown from the 20 genotypes evaluated in each experiment (greater water uptake rates are shown by black lines and lower water uptake rates by grey lines). Differences among high and low water uptake rate genotypes across each experiment, as determined by repeated measures and LSD $(P<0.05)$, are indicated by * to show significant differences from all three genotypes with contrasting water uptake rates.

Significant correlations with normalised final water uptake rates were observed only for root parameters (maximum root depth in Exp 1 and RDW in Exp 2). RSR was not correlated with water uptake in any experiment.

\section{Discussion}

Large and consistent genotypic differences in water uptake and plant growth under drought stress were observed in this diverse panel. The genotypes with greatest partitioning to deep roots were the genotypes with the greatest TWU. RLD at depth (Exp 1) was significantly correlated with both cumulative water uptake and water uptake rate at the end of the study. Water uptake patterns among genotypes remained consistent throughout the stress treatments, in which genotypes that had initially high water uptake rates were the same genotypes that showed high water uptake rates at the end of the study. The observed consistencies in genotypic rankings among studies of contrasting environmental conditions point to a strong genetic influence on water uptake patterns, and the important role of root architecture for water uptake under drought stress.

The three experiments differed in environmental conditions. In general, plants in Exp 2 were exposed to higher temperatures, greater radiation levels, lower relative humidity and later initiation of drought stress, in addition to being grown in a different soil type (Table 1). However, genotype rankings for water uptake ability were relatively consistent across experiments (Figs 2, 3, 4), and these trends were correlated with root growth (Table 4). These consistent rankings of genotypes throughout the drought-stress period were observed despite large differences in the phenologies of the genotypes studied, although all three experiments were harvested before the genotypes reached maturity. Genotypes from the $O$. sativa type aus group especially Dular - stood out as having greater root growth at 


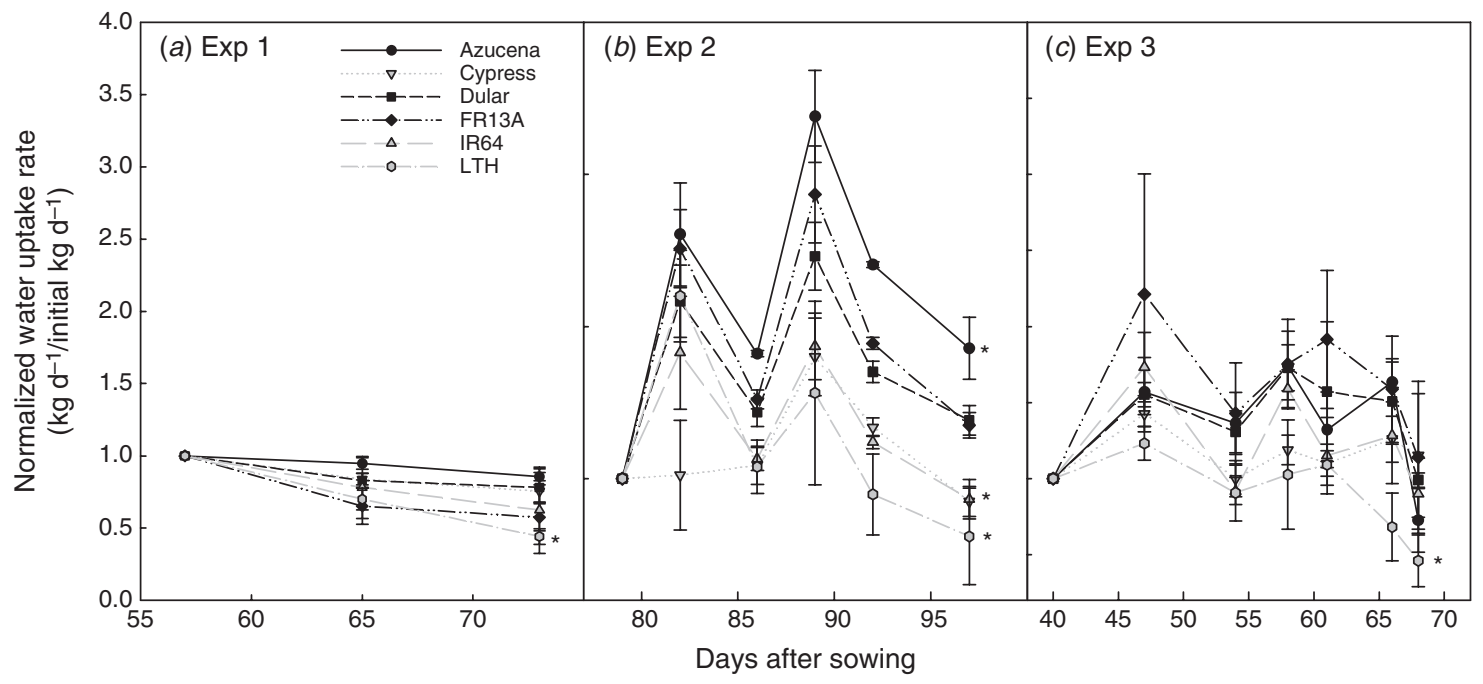

Fig. 4. Water uptake rates normalised for initial rate in $(a)$ Experiment $(\operatorname{Exp}) 1,(b) \operatorname{Exp} 2$ and $(c)$ Exp 3. For clarity, only the six most contrasting genotypes are shown from the 20 genotypes evaluated in each experiment (greater normalised water uptake rates are shown by black lines and lower normalised water uptake rates by grey lines). Differences among high and low normalised water uptake rate genotypes across each experiment, as determined by repeated measures and LSD $(P<0.05)$, are indicated by * to show significant differences from all three genotypes with contrasting water uptake rates. Note that different genotypes were found to be most contrasting for absolute and normalised water uptake rates.

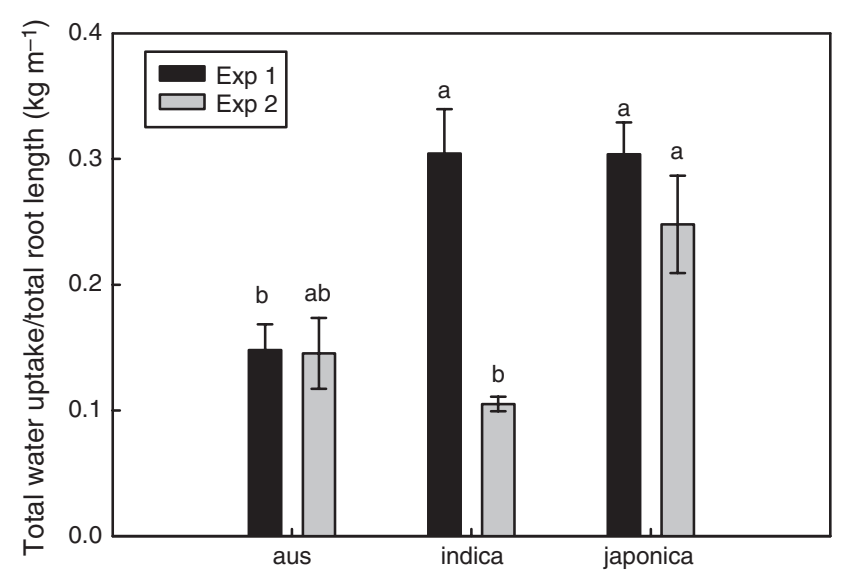

Fig. 5. Total water uptake per total root length in lysimeter Experiments 1 and 2 by type. In Experiment 1 (black), bars show the mean value of four $O$. sativa type aus, eight $O$. sativa type indica and eight $O$. sativa type japonica genotypes. In Experiment 2 (grey), bars show the mean value of two $O$. sativa type aus, three $O$. sativa type indica and four $O$. sativa type japonica genotypes. Letters indicate significant differences within each experiment.

depth (Table 2 and Fig. 1) or greater cumulative (Fig. 2) and daily water uptake (Fig. 3) than the other genotypes. These variations among rice types were also observed in the OryzaSNP panel in field studies at IRRI (Henry et al. 2011), although RLD values at depth were much greater in the lysimeters of our study than in the field. The greater ability of $O$. sativa type aus genotypes than of other rice types to exploit more soil moisture under drought stress could be explained by the differences in root distribution along the soil profile (Table 2). The relationship between root parameters and water uptake rates at the end of Exps 1 and 2 (Table 4) points to the importance of deep root growth for continuing the duration of water extraction from progressively drying soil. However, the significant but moderate correlations between RLD and water uptake highlight that water extraction is a distinct parameter from RLD, and is also affected by other plant functions (including hydraulic conductance and shoot biomass) and environmental effects (including light, temperature and evaporative demand).

These diverse rice genotypes showed large differences in TWU over the lysimeter experiments, but did not show differences in their patterns of water uptake. One exception was LTH, which showed high water use at early measurements that decreased to among the lowest by the end of each experiment (Fig. 3), which is likely due to its large shoot mass and shallow root distribution (Fig. 1, Table 2). The consistent water uptake patterns in this study are in contrast to previous drought-lysimeter studies in chickpea (Zaman-Allah et al. 2011a) or pearl millet (Pennisetum glaucum (L.) R. Br.) (Vadez et al. unpublished), in which genotypes showed hardly any differences in TWU but showed clear differences in water uptake patterns. In those studies, drought-resistant genotypes showed lower water uptake rates at the vegetative stage and before stress, but were able to maintain higher uptake rates past flowering and when plants were affected by stress. This differential response among crops may be related to the differences in drying dynamics of the soils (upland and lowland fields) to which they are adapted, resulting in divergent drought-resistance strategies between the two types of crops. Since drought-stressed lowland rice has more time to respond to drying soil than crops grown in upland soils, its adaptation to drought may be to adjust root depth to a progressively receding watertable. Conservative water use has been described as an important strategy for drought resistance in upland crops (Sadok and Sinclair 2009; Kholová et al. 2010; Zaman-Allah et al. 2011b), but our results indicate that lowland 
Table 4. Correlation matrix (Pearson correlations) between plant traits and water uptake

Significant correlations between parameters are indicated by * for $P<0.05, * *$ for $P<0.01$ and *** for $P<0.001$. TWU, total water uptake; WU, water uptake; SDW, shoot dry weight; RDW, root dry weight; RSR, root : shoot ratio; RLD, root length density; TRL, total root length

\begin{tabular}{|c|c|c|c|c|c|c|c|c|c|c|c|}
\hline & TWU & $\begin{array}{c}\text { Final } \\
\text { WU rate }\end{array}$ & $\begin{array}{l}\text { Normalised } \\
\text { final WU rate }\end{array}$ & SDW & RDW & RSR & $\begin{array}{l}\text { RLD 0- } \\
30 \mathrm{~cm}\end{array}$ & $\begin{array}{c}\text { RLD 30- } \\
45 \mathrm{~cm}\end{array}$ & $\begin{array}{l}\text { RLD 45- } \\
60 \mathrm{~cm}\end{array}$ & $\begin{array}{c}\text { RLD 60- } \\
100 \mathrm{~cm}\end{array}$ & $\begin{array}{l}\text { Max. root } \\
\text { depth (cm) }\end{array}$ \\
\hline \multicolumn{12}{|l|}{ Experiment 1} \\
\hline TWU & 1 & - & - & - & - & - & - & - & - & - & - \\
\hline Final WU rate & $0.86 * * *$ & 1 & - & - & - & - & - & - & - & - & - \\
\hline Normalised final WU rate & 0.13 & $0.45^{* * *}$ & 1 & - & - & - & - & - & - & - & - \\
\hline SDW & $0.49 * * *$ & $0.42 * * *$ & 0.1 & 1 & - & - & - & - & - & - & - \\
\hline RDW & $0.32 * *$ & $0.24 *$ & 0.05 & $0.46 * * *$ & 1 & - & - & - & - & - & - \\
\hline RSR & 0.08 & 0.07 & 0.05 & $-0.26^{*}$ & $0.61 * * *$ & 1 & & & & & \\
\hline RLD 0-30 & 0.24 & 0.18 & 0.04 & $0.39 * * *$ & $0.51 * * *$ & $0.39 * * *$ & 1 & - & - & - & - \\
\hline RLD 30-45 & $0.42 * * *$ & $0.28 *$ & -0.01 & $0.54 * * *$ & $0.66^{* * *}$ & $0.39 * * *$ & $0.65 * * *$ & 1 & - & - & - \\
\hline RLD 45-60 & $0.47 * * *$ & $0.39 * * *$ & 0.02 & $0.55 * * *$ & $0.74 * * *$ & $0.44 * * *$ & $0.54 * * *$ & $0.81^{* * *}$ & 1 & - & - \\
\hline RLD 60-100 & $0.43 * * *$ & $0.35^{* *}$ & -0.07 & $0.55 * * *$ & $0.61 * * *$ & $0.32 * *$ & $0.39 * * *$ & $0.74 * * *$ & $0.84 * * *$ & 1 & - \\
\hline Max. root depth & $0.39 *$ & $0.32 *$ & $0.40^{*}$ & $0.30^{*}$ & $0.33^{*}$ & 0.14 & 0.17 & 0.29 & $0.42 * *$ & $0.50 * * *$ & 1 \\
\hline \multirow[t]{2}{*}{ TWU TRL $^{-1}$} & -0.11 & -0.09 & -0.01 & $-0.28 *$ & -0.22 & 0.02 & $-0.28 *$ & $-0.3 *$ & $-0.31 *$ & $-0.26^{*}$ & -0.22 \\
\hline & TWU & $\begin{array}{c}\text { Final } \\
\text { WU rate }\end{array}$ & $\begin{array}{l}\text { Normalised } \\
\text { final WU rate }\end{array}$ & SDW & RDW & RSR & $\begin{array}{c}\text { RLD } \\
0-100 \mathrm{~cm}\end{array}$ & & & & \\
\hline \multicolumn{12}{|l|}{ Experiment 2} \\
\hline TWU & 1 & - & - & - & - & - & - & & & & \\
\hline Final WU rate & $0.79 * * *$ & 1 & - & - & - & - & - & & & & \\
\hline Normalised final WU rate & 0.07 & $0.54 * * *$ & 1 & - & - & - & - & & & & \\
\hline SDW & $0.43 * * *$ & $0.23 *$ & -0.09 & 1 & - & - & - & & & & \\
\hline RDW & 0.29 & $0.44^{*}$ & $0.39^{*}$ & $0.70 * * *$ & 1 & - & - & & & & \\
\hline RSR & -0.09 & -0.05 & -0.07 & -0.23 & $0.39 *$ & 1 & - & & & & \\
\hline RLD 0-100 & 0.25 & 0.26 & 0.11 & $0.46^{* *}$ & $0.62 * * *$ & 0.18 & 1 & & & & \\
\hline TWU TRL $^{-1}$ & -0.31 & -0.25 & 0.07 & -0.17 & -0.37 & -0.28 & $-0.56 * * *$ & & & & \\
\hline
\end{tabular}

rice does not show such a response to drought. Rather, the genotypes with greater root growth at depth (Table 2; Dular and Azucena) were able to maintain greater water uptake rates throughout the drought-stress treatments (Figs 3, 4).

Interestingly, the TWU of these rice genotypes (ranging from an average of $3.5-5.2 \mathrm{~kg}$ in Exps 2 and 3) was considerably lower than the TWU of other crops grown in the same lysimeter facility and under similar conditions as in Exp 2. A collection of drought-tolerant and sensitive chickpea genotypes grown in vertisol soil took up $\sim 8.3 \mathrm{~kg}$ water during a stress period from 23 to 75 days after sowing (Zaman-Allah et al. 2011a), and $A$. hypogaea genotypes grown to maturity under intermittent drought stress in alfisol soil took up $\sim 6.4 \mathrm{~kg}$ water (Ratnakumar et al. 2009). This reduced water uptake ability of rice is in agreement with Kondo et al. (2000), who observed that maize (Zea mays L.) extracted significantly greater amounts of water than rice based on soil moisture levels in a field study, which was attributed to differences in root growth at depth and water extraction per unit root length.

In this study, we observed genotypic differences in the ability to extend root growth at depth in response to drought stress, as well as differences in water uptake ability per length of root. However, the genotypes with the greatest root growth at depth were not consistently the genotypes with the greatest cumulative or daily water uptake. For example, N22 showed consistently high RDW (Fig. 1) and had a high RLD below $45 \mathrm{~cm}$ in Exp 1 (Table 2), but showed greater water uptake rates only in Exp 2. This may be due to the different environmental conditions in Exp 2 , in which plants experienced the highest solar radiation and temperature, and the longest period of drought-stress application; $\mathrm{N} 22$ has been identified as one of the most heat-tolerant rice genotypes in terms of grain yield and spikelet fertility (Prasad et al. 2006; Jagadish et al. 2008). Although rice appears to have a lower water extraction ability per length of root than other crops, we did observe genetic variation for TWU TRL ${ }^{-1}$ (Fig. 5), for which $O$. sativa type japonica genotypes showed the greatest $\mathrm{TWU} \mathrm{TRL}^{-1}$. These differences may be due to differences in root morphology among rice types (Lafitte et al. 2001; Uga et al. 2009), but are probably also affected by aboveground responses to drought.

Shoot growth and stomatal conductance drive water uptake. We observed large variation in SDW among genotypes, and this was highly correlated with water uptake (Table 4). Since large plants are expected to take up more water due to allometric (size) effects, we normalised water uptake rates by the initial water uptake rate at the onset of drought stress, in order to factor out the size effect and observe any additional root distribution effects on water uptake. This size effect was apparent in our study, as shown by the differences in genotypes identified as most contrasting in the non-normalised and normalised water uptake rates (Figs 3,4). Normalising for shoot size at the time of weighing would be an improved lysimetric method for comparing water uptake of genotypes of contrasting size. Also, more detailed monitoring of ambient conditions could be useful for normalisation to reduce variation in data between measuring dates due to fluctuations in temperature, light levels and relative humidity that affect water uptake. 
Our plant growth results differ from those of Asch et al. (2005), who evaluated the RSR in rice under drought stress in similarly large lysimeters but under upland conditions, and reported changes in root distribution with depth but no change in RSR between drought-stress and well watered treatments. In addition to differences in RSR among experiments and treatments, we also observed differences in RSR among genotypes. Moroberekan showed the strongest increase in RSR, but this did not result in greater water uptake. The lack of correlation between water uptake and RSR in all conditions is most likely due to the large diversity of the OryzaSNP panel and also because RSR is a bulk measurement that does not reflect root distribution in the soil profile or the dynamics of water uptake. Our results suggest that increasing total root growth relative to shoot growth does not necessarily result in increased water uptake under drought.

Since greater water uptake under drought was related to deep root growth in our study, the genotypes with higher water uptake rates were likely to show smaller yield reductions under drought in the field. Genotype Dular was identified as having some of the highest water uptake rates and root length densities at depth under drought stress in the lysimeters. In lowland drought evaluations of the OryzaSNP panel in the field, Henry et al. (2011) reported consistently high values for Dular in terms of the drought-response index, which is a relative comparison of yield under drought. The absolute water uptake and root length density measurements reported here may be a more reliable indicator of drought resistance than water extraction per length of root, since $O$. sativa type japonica types showed the highest TWU TRL ${ }^{-1}$ but did not stand out for higher drought resistance in the field (Henry et al. 2011). In addition to the previously reported drought tolerance of Dular in terms of the drought response index, genotype N22 has also been characterised as a drought tolerance donor, contributing a major effect droughtyield quantitative trait locus to multiple drought-susceptible backgrounds including IR64 and Swarna (Vikram et al. 2011).

In summary, 20 diverse rice genotypes of the OryzaSNP panel were evaluated for water uptake ability under drought in three greenhouse lysimeter studies. TWU and water uptake rates at the end of the drought stress treatment were correlated with RLD, especially at depths below $30 \mathrm{~cm}$. Water uptake rates varied among genotypes, as did water uptake per length of root. Patterns of water uptake were relatively consistent among genotypes across the drought-stress period, pointing to the importance of lowland rice's response to drought in terms of deeper root growth rather than conserving water by limiting water uptake. Subsequent work with the OryzaSNP panel will use these data to help identify the genetics behind rice root growth and function for water uptake in response to drought, and to study possible associations between root traits and grain yield under drought stress.

\section{Acknowledgements}

We thank J. Villa, G. Dimayuga and R. Torres for their technical assistance and K. L. McNally for his suggestions and coordinating the OryzaSNP project. We thank the drought physiology team at ICRISAT for their valuable suggestions and help during Exp 2. We acknowledge the assistance from the Barwale Foundation, Hyderabad. This work was funded by the Generation Challenge
Program (Project G3005.01) and the Bill and Melinda Gates Foundation project 'Stress-Tolerant Rice for Africa and South Asia.'

\section{References}

Asch F, Dingkuhn M, Sow A, Audebert A (2005) Drought-induced changes in rooting patterns and assimilate partitioning between root and shoot in upland rice. Field Crops Research 93, 223-236. doi:10.1016/j.fcr.2004. 10.002

Gowda VRP, Henry A, Yamauchi A, Shashidhar HE, Serraj R (2011) Root biology and genetic improvement for drought avoidance in rice. Field Crops Research 122, 1-13. doi:10.1016/j.fcr.2011.03.001

Haefele SM, Siopongco JDLC, Boling AA, Bouman BAM, Tuong TP (2009) Transpiration efficiency of rice (Oryza sativa L.) Field Crops Research 111, 1-10. doi:10.1016/j.fcr.2008.09.008

Henry A, Gowda VRP, Torres RO, McNally KL, Serraj R (2011) Variation in root system architecture and drought response in rice (Oryza sativa): phenotyping of the OryzaSNP panel in rainfed lowland fields. Field Crops Research 120, 205-214. doi:10.1016/j.fcr.2010.10.003

Hirasawa T, Ishihara K (1991) On resistance to water transport in crop plants for estimating water uptake ability under intense transpiration. Nihon Sakumotsu Gakkai Kiji 60, 174-183. doi:10.1626/jcs.60.174

Impa SM, Nadaradjan S, Boominathan P, Shashidhar G, Bindumadhava H, Sheshshayee MS (2005) Carbon isotope discrimination accurately reflects variability in WUE measured at a whole plant level in rice. Crop Science 45, 2517-2522. doi:10.2135/cropsci2005.0119

Jagadish SVK, Craufurd PQ, Wheeler TR (2008) Phenotyping parents of mapping populations of rice for heat tolerance during anthesis. Crop Science 48, 1140-1146. doi:10.2135/cropsci2007.10.0559

Jahn CE, Mckay JK, Mauleon R, Stephens J, McNally KL, Bush DR, Leung H, Leach JE (2011) Genetic variation in biomass traits among 20 diverse rice varieties. Plant Physiology 155, 157-168. doi:10.1104/pp.110. 165654

Kamoshita A, Wade L, Yamauchi A (2000) Genotypic variation in response of rainfed lowland rice to drought and rewatering: 3. Water extraction during the drought period. Plant Production Science 3, 189-196. doi:10.1626/pps.3.189

Kamoshita A, Babu RC, Boopathi NM, Fukai S (2008) Phenotypic and genotypic analysis of drought-resistance traits for development of rice cultivars adapted to rainfed environments. Field Crops Research 109, 1-23. doi:10.1016/j.fcr.2008.06.010

Kato Y, Okami M (2011) Root morphology, hydraulic conductivity and plant water relations of high-yielding rice grown under aerobic conditions. Annals of Botany 108, 575-583. doi:10.1093/ $\mathrm{aob} / \mathrm{mcr} 184$

Kholová J, Hash CT, Kumar PL, Yadav RS, Kočová M, Vadez V (2010) Terminal drought-tolerant pearl millet [Pennisetum glaucum (L.) R. Br] have high leaf $\mathrm{ABA}$ and limit transpiration at high vapour pressure deficit. Journal of Experimental Botany 61, 1431-1440. doi:10.1093/ jxb/erq013

Kondo M, Murty MVR, Aragones DV (2000) Characteristics of root growth and water uptake from soil in upland rice and maize under water stress. Soil Science and Plant Nutrition 46, 721-732. doi:10.1080/00380768.2000. 10409137

Lafitte RH, Champoux MC, McLaren G, O'Toole JC (2001) Rice root morphological traits are related to isozyme groups and adaptation. Field Crops Research 71, 57-70. doi:10.1016/S0378-4290(01) 00150-2

Lilley JM, Fukai S (1994) Effect of timing and severity of water deficit on four diverse rice cultivars. I. Rooting pattern and soil water extraction. Field Crops Research 37, 205-213. doi:10.1016/0378-4290(94) 90099-X

Lynch JP (2007) Roots of the second green revolution. Australian Journal of Botany 55, 493-512. doi:10.1071/BT06118 
McNally KL, Childs KL, Bohnert R, Davidson RM, Zhao K, Ulat VJ, Zeller G, Clark RM, Hoen DR, Bureau TE, Stokowski R, Ballinger DG, Frazer KA, Cox DR, Padhukasahasram B, Bustamante CD, Weigel D, Mackill DJ, Bruskiewich RM, Ratsch G, Buell CR, Leung H, Leach JE (2009) Genomewide SNP variation reveals relationships among landraces and modern varieties of rice. Proceedings of the National Academy of Sciences of the United States of America 106, 12273-12278. doi:10.1073/ pnas.0900992106

O'Toole JC, Bland WL (1987) Genotypic variation in crop plant root systems. Advances in Agronomy 41, 91-145. doi:10.1016/S00652113(08)60803-2

Parent B, Suard B, Serraj R, Tardieu F (2010) Rice leaf growth and water potential are resilient to evaporative demand and soil water deficit once the effects of root system are neutralized. Plant, Cell \& Environment 33, $1256-1267$.

Prasad PVV, Boote KJ, Allen LH Jr, Sheehy JE, Thomas JMG (2006) Species, ecotype and cultivar differences in spikelet fertility and harvest index of rice in response to high temperature stress. Field Crops Research 95, 398-411. doi:10.1016/j.fcr.2005.04.008

Puckridge DW, O'Toole J (1980) Dry matter and grain production of rice, using a line source sprinkler in drought studies. Field Crops Research $\mathbf{3}$, 303-319. doi:10.1016/0378-4290(80)90037-4

R Development Core Team (2010) 'A language and environment for statistical computing.' (R Foundation for Statistical Computing: Vienna).

Ratnakumar P, Vadez V (2011) Groundnut (Arachis hypogaea L.) genotypes tolerant to intermittent drought maintain a high harvest index and have small leaf canopy under stress. Functional Plant Biology 38, 1016-1023. doi:10.1071/FP11145

Ratnakumar P, Vadez V, Nigam SN, Krishnamurthy L (2009) Assessment of transpiration efficiency in peanut (Arachis hypogaea L.) under drought using a lysimetric system. Plant Biology 11, 124-130. doi:10.1111/ j.1438-8677.2009.00260.x

Sadok W, Sinclair T (2009) Genetic variability of transpiration response to vapor pressure deficit among soybean cultivars. Crop Science 49, 955-960. doi:10.2135/cropsci2008.09.0560
Sanchez PA (1973) Puddling tropical rice soils: 2. Effects of water losses. Soil Science 115, 303-308. doi:10.1097/00010694-197304000-00006

Serraj R, Kumar A, McNally KL, Slamet-Loedin I, Bruskiewich R, Mauleon R, Cairns J, Hijmans RJ (2009) Improvement of drought resistance in rice. Advances in Agronomy 103, 41-99. doi:10.1016/ S0065-2113(09)03002-8

Serraj R, McNally KL, Slamet-Loedin I, Kohli A, Haefele SM, Atlin G, Kumar A (2011) Drought resistance improvement in rice, an integrated genetic and resource management strategy. Plant Production Science 14, 1-14. doi:10.1626/pps.14.1

Uga Y, Ebana K, Abe J, Morita S, Okuno K, Yano M (2009) Variation in root morphology and anatomy among accessions of cultivated rice (Oryza sativa L.) with different genetic backgrounds. Breeding Science 59, 87-93. doi:10.1270/jsbbs.59.87

Vadez V, Rao S, Kholová J, Krishnamurthy L, Kashiwagi J, Ratnakumar P, Sharma KK, Bhatnagar-Mathur P, Basu PS (2008) Roots research for legume tolerance to drought: quo vadis? Journal of Food Legumes 21, $77-85$.

Vikram P, Swamy BPM, Dixit S, Ahmed HU, Sta Cruz MT, Singh AK, Kumar A (2011) $q D T Y_{1.1}$, a major QTL for rice grain yield under reproductivestage drought stress with a consistent effect in multiple elite genetic backgrounds. BMC Genomics 12, 89.

Wade LJ, McLaren CG, Quintana L, Harnpichitvitaya D, Rajatasereekul S, Sarawgi AH, Kumar A, Ahmed HU, Sarwoto, Singh AK, Rodriguez R, Siopongco J, Sarkarung S (1999) Genotype by environment interactions across diverse rainfed lowland rice environments. Field Crops Research 64, 35-50. doi:10.1016/S0378-4290(99)00049-0

Zaman-Allah M, Jenkinson DM, Vadez V (2011a) A conservative pattern of water use, rather than deep or profuse rooting, is critical for the terminal drought tolerance of chickpea. Journal of Experimental Botany 62, 4239-4252. doi:10.1093/jxb/err139

Zaman-Allah M, Jenkinson DM, Vadez V (2011b) Chickpea genotypes contrasting for seed yield under terminal drought stress in the field differ for traits related to the control of water use. Functional Plant Biology 38, 270-281. doi:10.1071/FP10244 